\title{
PARASITOS METAZOÁRIOS DE Plagioscion squamosissimus (HECKEL, 1840) CAPTURADOS NO RESERVATÓRIO DE PROMISSÃO, RIO TIETÊ
}

\author{
METAZOAN PARASITE OF Plagioscion squamosissimus (HECKEL, 1840) \\ CAPTURED IN PROMISSÃO RESERVOIR, TIETE RIVER
}

\author{
I. M. LAPERA ${ }^{1}{ }^{*}$, A. C. SILVA ${ }^{1}$, J. H.; TEBALDI ${ }^{1}$, E. G. L. HOPPE ${ }^{1}$
}

\section{RESUMO}

A corvina, natural da bacia Amazônica, foi introduzida recentemente no Rio Tietê devido ao seu potencial para a pesca. O objetivo deste trabalho foi caracterizar e analisar as comunidades e infracomunidades de parasitas metazoários de corvinas capturadas no Reservatório de Promissão, no Rio Tietê, situado em Borborema-SP. Foram examinados 50 espécimes de corvina, com comprimento padrão médio de 25,21 \pm $2,27 \mathrm{~cm}$ e peso médio de 328,82 $\pm 89,03 \mathrm{~g}$, capturados no mês de Março de 2015 por pescadores profissionais com auxílio de redes artesanais. Os peixes foram acondicionados em caixas isotérmicas com gelo, e transportados até o Laboratório de Enfermidades Parasitárias do Departamento de Medicina Veterinária Preventiva, Faculdade de Ciências Agrárias e Veterinárias de Jaboticabal (FCAV), onde foram medidos, pesados e submetidos a necropsia parasitológica. Os parasitas obtidos foram quantificados, preparados e montados para identificação taxonômica. A partir desses dados, foram realizadas as análises das comunidades de parasitos. Foram coletados 5227 espécimes de parasitas metazoários, sendo 2880 (55,1\%) Diplectanum piscinarius (Monogenoidea: Diplectanidae) e 2347 (44,9\%) metacercárias de Austrodiplostomum compactum (Digenea, Diplostomidae), ambos com prevalência de $100 \%$ e abundância parasitária de 57,6 e 46,9, respectivamente. Foi encontrada baixa diversidade parasitária (riqueza de espécies=2), com índice de Simpson (D) igual a 0,505 e baixos valores dos índices de Shannon $\left(H^{\prime}=0,688\right)$ e de diversidade de Margalef $(\mathrm{I}=0,177)$. O índice de dominância de Berger-Parker $(\mathrm{d}=0,551)$ indicou leve dominância do monogenético. Houve correlação positiva intermediária, avaliada pelo coeficiente de Pearson, entre a abundância parasitária de $D$. piscinarius e comprimento padrão $(r=0,43)$ e peso $(r=0,51)$ dos hospedeiros. O presente estudo permite inferir que os parasitos monogenéticos e digenéticos são predominantes na comunidade parasitária de corvinas do Reservatório de Promissão. Também pode-se afirmar que peso e comprimento padrão do hospedeiro influenciam a intensidade do parasitismo por $D$. piscinarius em corvinas, com correlação positiva intermediária para ambos parâmetros biométricos.

PALAVRAS-CHAVE: Austrodiplostomum compactum. Diplectanum piscinarius. ECOLOGIA PARASITÁRIA. PEIXE DE ÁGUA DOCE. CORVINA.

\section{AGRADECIMENTOS: CAPES}

ÁREA TEMÁTICA: Doenças parasitárias

\footnotetext{
${ }^{1}$ Faculdade de Ciências Agrárias e Veterinárias da Universidade Estadual Paulista (UNESP) - Câmpus de Jaboticabal

*e.hoppe@gmail.com
} 